\title{
Identity Value of Reformation Era Strives on the Sign-system of Trisakti University Campus
}

\author{
Virginia Suryani \\ Faculty of Art and Design \\ Trisakti University \\ niaaja@yahoo.com
}

\author{
Wegig Murwonugroho \\ Faculty of Art and Design \\ Trisakti University \\ wegig_besar@yahoo.com
}

\begin{abstract}
Sign system is a type of signage which serves as a means of communication. It has a function to show identity, information, and direction. The Trisakti University is a private campus known as the Reformation campus. The beginning of the reformation era caused by the unrestrained anger of the people for the shooting of 4 (four) students. It is a significant moment until the fall of the New Order dictatorship. The value obtained from this research is the spirit of patriotism, pioneer, courage to defend the truth, and other nationalism spirit. The identity as a reformation campus can be a modality that plausible to be stated in the Trisakti University campus sign system. Descriptive analysis method was used in this study. This analysis is a guide in designing campus sign systems. Sign system become an instrument to establish the imaging of the campus. The sign system does not stand alone, but is able to generate positive responses from the academic community and visitors. Eventually, values of nationalism spirit become the concept of novelty in the design of the sign system.
\end{abstract}

Keywords: sign system, reformation, campus

\section{BACKGROUND}

Sign system is a spatial tagging system, both inside and outside outdoor, which indicates a spatial identity. Signs, symbols, and images have been used by humans as a means of communication. Through visual images, humans interpret and understand the meaning of signs and symbols. Semiotics becomes a tool for interpreting messages hidden in symbols, signs, images, gestures, spatial, and icons (Ismail, 2017: 356)

The sign system also functions as a pointing device that directs or helps people to know their position and where will they go. People who come by for the first time or do not know a place very well yet are those who need sign systems. Trisakti University is a national private campus. Momentum of the Reformation event on $12^{\text {th }}$ May 1998 began on this campus. 4 (four) Trisakti University students were shot dead. This incident sparked people's anger over the despotic security apparatus. Finally, 32 years ruling of the New Order was overthrown by the persistence of students who demanded for changes. The country is expected to be free from the elements of Corruption, Collusion and Nepotism. Willing to sacrifice, dare to defend the truth, togetherness of students and people become the spirit of reformation.

Campuses of Trisakti University in Jakarta consists of Campus A in Grogol, Campus B next to Sumber Waras Hospital, and Campus F in Rawamangun. This research is devoted to analyzing campus A. There are 2 (two) main points of access to Trisakti University Campus A, namely: 1). Gate 1 (entering across the Grogol bus terminal) and, 2). Gate 2 (opposite side of Ciputra Mall). Right and left side of the campus entrance are accented with cylindrical rocks used by concrete test. When people entering the gate, there is uncertainty whether this is the entrance or the exit; whether this is two lanes or only one direction.

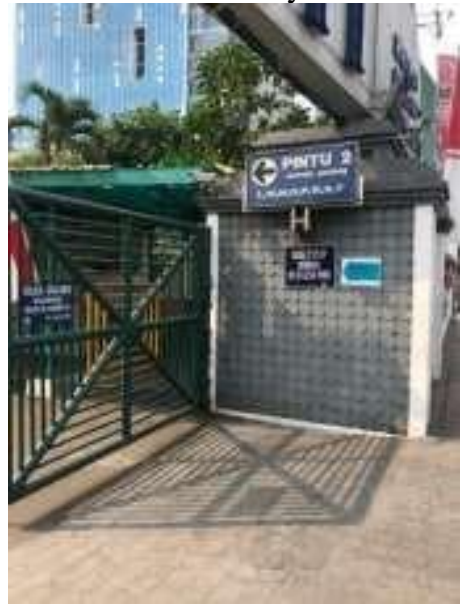

Figure 1. The gate of Trisakti University on the opposite side of Ciputra Mall

(Source: Personal Photos)

Ideally, a gate has to be explicitly distinct, whether the road can only be passed just as an entrance or also as an exit for vehicles. This means that the exit must be seen architecturally. Surely if the entrance is overlooked then it will make someone hesitant to enter or even missed it, so they have to turnover to past the traffic jam in Jakarta. Furthermore, when entering the parking lot, there is no clear division of public parking areas, areas for students, or for the lecturers.

Tosca green accented pergolas existed as the access from Gate 2 to the campus. The location map is 
vaguely readable, and the position of the person who reads it is unknown.

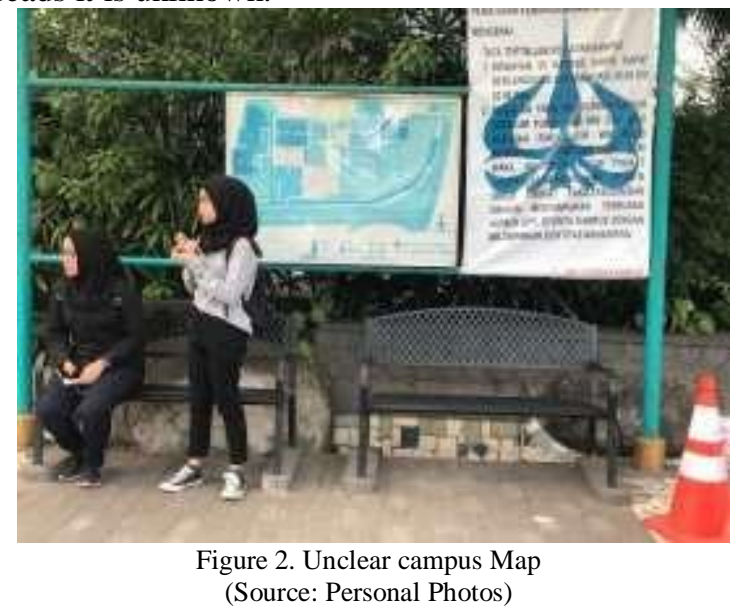

This lack of clarity makes people have to ask officers in-charge. Information deadlock will occur when people ask other people or security guards who sometimes do not know the location of the faculty. It is possible if there are several faculties under one roof. Crowded and tight campus buildings also makes it difficult for people to find certain location. Therefore, this is the problem which rises the importance of sign system. First problem, the sign system has not been structured yet. Second problem is the absence of typical sign system guidelines, shape, color, type of font, and other graphic elements.

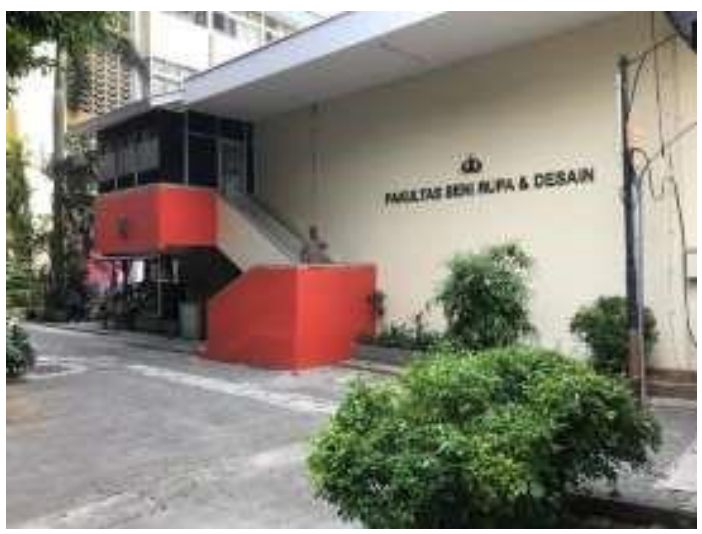

Figure 3. Design, shapes, coloring, and untraceable building designation, made them difficult for visitors to find a location. (Source: Personal Photos)

Sign systems can actually be a branding of the existence of a campus. This means that when the campus has a well-structured sign system and optimally processes its elements, the school branding will looked better. It is the need for a study on how to design interesting, informative, and distinctive features of sign system. This characteristic will differentiate Trisakti University from other campuses. Sign system identity is the third problem in this study.
Campus is an area of interaction between lecturers, students, and other academics. It becomes a public space when the public becomes an element of the physical environment. The sign system that occupies public space must be easily accessible, visible, integrated with the environment, and stimulates a positive response from the public; in this case, the academic community. The interaction between sign systems and the public is the fourth problem. Sign system spatial design should not only aesthetically good but also provide a comfortable environment for people who pass through it (Maruthaveeran, 2010: 205).

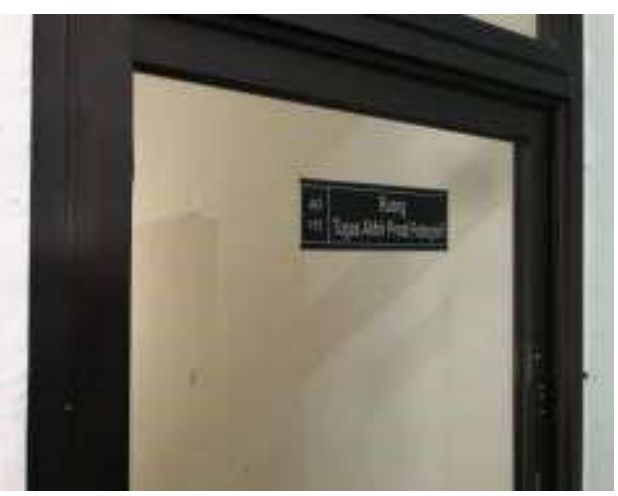

Figure 4. Less than attractive sign system in the lecturer room in terms of font selection, shape, and color (Source: Personal Photos)

\section{DATA OVERVIEW}

Trisakti University Campus A is located on $\mathrm{Jl}$. Kyai Tapa 1 Grogol, West Jakarta. On the north side there is the Grogol bus terminal, on the west side there is Ciputra Mall, and on the south side adjacent to Tarumanegara University. Trisakti University consists of 9 (nine) faculties at D3, S1 and postgraduate levels. Trisakti University as a national campus is not based on a particular religion, nor the dominance of certain ministries. The $12^{\text {th }}$ May 1998 tragedy monument and the Reformation Museum became the campus identity. From observations on the field of identity, this 'reformation' does not appear in other buildings, except the $\mathrm{M}$ building where the Reformation Museum is located. The museum is marked with several signs, such as: bullet marks through the glass, spilled blood, and the shape of a bullet shell.

The term 'Campus of Reformation' becomes an identity, a characteristic that distinguishes Trisakti University campus from others. Some universities in Yogya explore batik or wayang as their identity. University in Kalimantan explores Dayak ornaments, University in Bogor explores the form of Kujang weapons typical of West Java. This means that Trisakti University must explore its identity. A strong identity of Trisakti is as the reformation university. It must be realized that related with the Sign system, it must be seen from the positive side, not negative. This means 
that there should be no historical trauma issue or other disruptive things. But it must raise the spirit of patriotism and nationalism, especially for students. The value of 'reformation' has the highest potential to be lifted. The context of the courage of students in upholding truth and justice is a passion for students to continue to maintain the truth in this country.

\section{Theoretical Basis \\ Sign system}

Definition of sign system is a series of visual representations and graphic symbols that aim to be a medium for human interaction with public space (Tinarbuko, 2012: 12). The sign system is divided into three areas, 1.) Public Area; 2.) Semi-public Area; and 3.) Private Area. Public areas tend to be outdoor. Semipublic areas are spaces accessible for guests. Private Area is a special room for class, specifically for lecturers, meeting, or student consultation room.

Sign system facilitates campus access and services. It is useful to mitigate its guests to wonder about their location, especially for people who visit for the first time (Omar, D'Silva, and Bolong, 2018: 110).

The icon that appears in the sign system becomes a visual metaphor, as a tool to summarize long narrative sentences in written text into a more stylish appearance (Aston and Savona, 2013: 11).

An expression of "Should not Parking Here" is represented by the crossed letter P mark.

In fact "Language" is one form of sign system that people use to mediate and regulate the world. The concept of language and society initiates instructions on the sign system and copies them into social reproduction (Calefato, 2009: 48). This means that the sign system is structured and adapted to the sociocultural character in the community. All objects, languages, and real-world events can be arranged in a sign system. There is no explanation of the reality outside the world of ideas (Fulton, 2005: 231). Furthermore, the sign system is arbitrariness that allows language to become an abstract system that is self-regulating and capable of transformation (Aston and Savona, 2013: 6). This means that the aspect of creativity allows making the sign system more attractive.

Sign system will be responded by the public on campus. There are three levels of information processing, namely: 1). Visceral; 2). Behavioral; and 3) Reflective. Level 1). Visceral, refers to the 'spontaneous' user's response to the appearance of an object through the five senses of the human being without conscious. At this level, humans recognize objects based on biological reactions.

Level 2). Behavioral, shows human behavior related to the function and use of an object. In this level, 'expectation-induced' on the features and functionality of an object that comes from the experience gained through the daily learning process. At this level, people's responses to each other will differ based on one's cultural background.

Level 3). Reflective, comes from reflecting a person's reasoning process regarding an object. Responses at this level are consciously carried out using intellectual processing. These three response levels interact with each other and form actions between users towards Sign system (Zolkifly and Hussin, 2017: 53).

Social Semiotics

This study seeks to present the text concerning one form of communication research practice with a qualitative approach based on 'text'. Examples of such forms of practice, specifically focused on text analysis with social semiotics methods in the MAK Halliday version. Social Semiotics from M.A.K. Halliday and Ruqaiya Hassan in the analysis of media content, were to find things related to the three components of Social Semiotics, namely: 1). Field of Discourse; 2). Tenor of Discourse; and 3). Mode of Discourse.

In terms of 1). Field of Discourse, aims to find out what is used as a discourse on the sign system. What will an object of Sign system be treated? Related 2). Tenor of Discourse, to find out the people listed in the text (nameplate, directions, etc.); the nature of these people, their position and role. A sign system will be an object that describes who and how the human subject is being correlated. 3). Mode of Discourse, to find out the part played by language: how the communicator (sign system) uses the style of language to describe the terrain of the situation and the people who involved (Halliday and Hasan, 1994: 15).

\section{RESULT AND DISCUSSION \\ Field of Discourse}

When someone visits a campus, the discourse that emerges is how the infrastructure facilitates the teaching and learning process. On the outdoor side, for example, how the building looks sturdy, modern, wellmaintained, decorated by a garden that gives the academic community room to interact that supports not only the teaching and learning process, but also the activities of art, sports, and other humanist activities. Students want to enjoy their youth too. Thus, the presence of the sign system has a role to support the presence of this atmosphere. Sign system is not only an informative sign, but a visual element that has value. Whether beautifying spatial planning, becoming a medium to convey moral or social messages. The strength of aesthetic elements makes new awareness in design. 

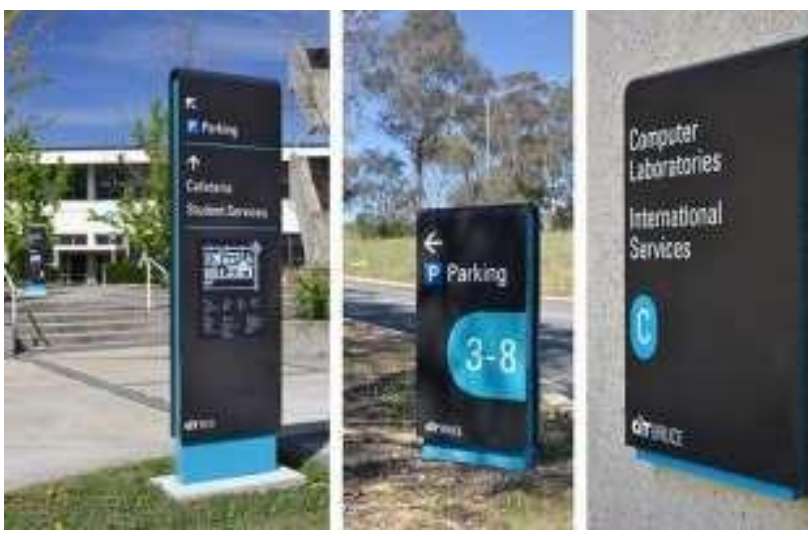

Figure 5. Consistency of design, shape, color, and font at some point in campus location makes it easy for readers to understand information.

\section{TENOR OF DISCOURSE}

Sign system cannot be separated from the identity of the corporate logo. Trisakti University has a logo consisting of logogram and logotype forms. Based on some media, there are still inconsistencies. First, the identity of "Trisakti University" needs font logotype. By far, Trisakti University has no provision for the type of letters used. It is necessary to have a Graphic Standard Manual. The content consists of arrangement of letters, colors, and applications in various media.

Sign system will be a signage that can describe who and how one icon with the other icon correlates. Inside the campus there are hierarchies from the level of the rector, faculty, to the department or study program. Likewise, there are hierarchies of deans, vice deans, and other structural officials. The distribution of graphic element patterns are arranged by paying attention to the hierarchy. For example, a building owned by the General Medical Faculty with a green identity will design a sign system with a predominantly green color as well. The green color will be a transparent layer that overrides the derivative color or image in the sign system. It does not need further exploration on color composition because there are identical color derivatives. As an example of a backdrop of a color zone at the 2018 Asian Games event. Green zone is dominated by the dominance of green and its supporting color elements, such as: bluish green, purplish green, brownish green, or other green. Visitors will still see that it is a green zone.

Distinction between buildings on campus will be more visible if the map is illustrated with 3 dimensional vector style. The building is not only in the form of a square illustration. 3 dimensional vector illustration will ease visitors to memorize the shape of the architectural facade.

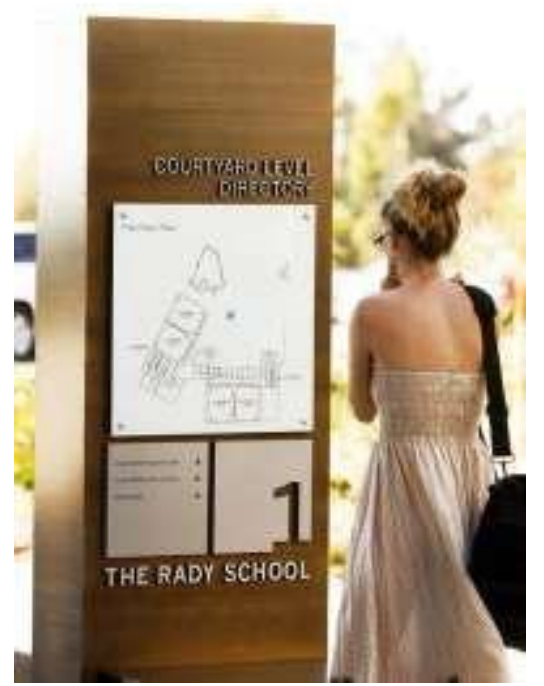

Figure 6. Sign system that provides the "You are Here" positioning makes it easier for the reader to know their location and direction (Pinterest)

\section{MODE OF DISCOURSE}

Sign system media field of can be used to put slogans or images with nationalism discourse relating to reformation. So media is not limited to a one-way communication media, but it stimulates those who see it to respond. Be aware of social messages or moral roles. Sign systems must be easy to read and understandable by all who pass by (Klimova, 2018: $585)$.

The presence of sign systems in public spaces are not as milestone or a disturbing physical form. It can be processed in such a way to be a concentration area for public dialogue. Narcissistic culture with interesting backgrounds can be an orientation in visual design.

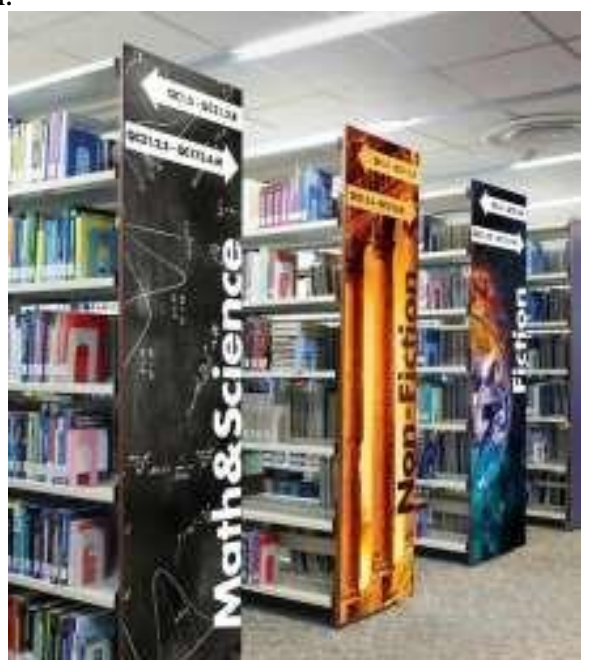

Figure 7. Sign system in library with a touch of visual design and color according to the category of book collection (Pinterest) 
Lecturers will feel more appreciated if a silhouette portrait themselves appear in the room, or an icon that the lecturer likes. Thus, the lecturer will feel proud of their identity if in every room. That identity becomes a unique sign.

The theme of the Sign system can be designed in a seasonal manner. The concentration is on the environment where there is always a graphic ornament of trees, twigs, or leaves in a season. In certain seasons, it is replaceable with batik ornamental or digital. Thus, the sign system design must be emphasized on the material. Possibly, the material is made to be easily to apply and remove. Because there is a shift in some lecturer positions, where the lecturer serves, the lecturer moves the room, the lecturer supervises a particular place, etc. so that it will be easy also how to make a sign system also easily reinstalled.

\section{CONCLUSION}

Sign system is one of the visual appearance media that can improve the image of a campus. The campus is not only limited to the learning and teaching process space, but also becomes a space for socializing, art and other humanist activities (Field of Discourse). The processing of the sign system's aesthetic elements that concept will make the campus that looks to have neatly arranged spatial information. Sign systems that are in public spaces must really pay attention to the Tenor of Discourse. Sign system is an important aesthetic element of a marker that is not just informative. The heroic illustration of the reform era became the identity of the Trisakti University Campus. Nationalist spirit of nationality into the mode of discourse embedded in the sign system can inspire its academic community in carrying out their duties.

\section{Acknowledgement}

The writing team would like to thank Trisakti University for its assignment in submitting research on sign systems at Trsiakti University Campus A Jakarta.

\section{REFERENCES}

Aston, Elaine and George Savona, Theatre as SignSystem: A Semiotics of Text and Performance, Routledge, USA, 2013.

Calefato, Patrizia, Language in Social Reproduction: Sociolinguistics and Sociosemiotics, Tartu University Press, Estonia, 2009.

Fulton, Helen, Narrative and Media, Cambridge University Press, New York, USA, 2005.

Halliday., M.A.K. and Ruqaiya Hasan, Bahasa, Konteks, dan Teks, Aspek-Aspek Bahasan dalam Pandangan Semiotik Sosial, Gadjah Mada University Press, Yogyakarta, Indonesia, 1994.

Ismail, Nurrissammimayantie, Rozaimah Rashidin and Amirah Ahmad, "Integrating Visual Semiotics in Interpretation of "Tugu Negara", Pertanika Journal, Malaysia, 2017.

Klimova, Blanka, "Tourists with Dementia - A Unique Challenge for the Tourism Industry", Pertanika Journal, Malaysia, 2018

Maruthaveeran, Sreetheran, "Establishing Performance Indicators from the User Perspective as Tools to Evaluate the Safety Aspects of Urban Parks in Kuala Lumpur", Pertanika Journal, Malaysia, 2010.

Omar, Siti Zobaidah, Jeffrey Lawrence D'Silva and Jusang Bolong, "Impingement Factors of Rural Library Services on Community Lifestyle in Malaysia", Pertanika Journal, Malaysia, 2018.

Zolkifly, Nur Hazwani and Md Nasarudin Hussin, "Digital Display of Car Showroom: Proposing an Emotional-Environmental Conceptual Model", Pertanika Journal, Malaysia, 2017. 